\title{
Beyond Entertainment: Novels and Film Adaptations in the ESL/EFL Classroom
}

\author{
Elisabeth Gareis, Martine Allard, \\ Susan Gill, and Jacqueline Saindon
}

This article explores techniques for use with longer works of literature and their film versions. Activities include discussions and writing assignments exploring the content of the selected novel or play, whole language exercises combining skill practice with social interactions, a video project allowing students to assume the roles of actors and crew members in their own production of the novel or play, and language learning tasks accompanying the viewing of the novel's or play's movie adaptation.

Students of English as a second or foreign language (ESL/EFL) often ask to read longer works of literature and watch movies as part of their classes. Because many novels and plays have been made into films (e.g., Black Robe, The English Patient, Field of Dreams), the two media are easily combined. In tandem they offer myriad opportunities for intensive, contextualized involvement and holistic learning. Yet some teachers are reluctant to use literature and film in their classes, in part because few textbooks are available that accompany reading novels or plays and viewing movies. With a little preparatory work, however, teachers can create their own activities and capitalize on the media's potential as well as cater to the individual needs of their students.

The following suggestions show how novels or plays and their movie versions can be used in the ESL/EFL classroom. Activities address all four skill areas (listening, speaking, reading, and writing) as well as a wide variety of teaching and learning styles (through individual work and collaboration, critical analysis and affective sharing, artistic expression, reflection, the use of technology, and other modes of learning). To illustrate the suggested techniques, we are using examples from Kosinski's (1971) novel Being There and its film adaptation starring Peter Sellers (Gareis, Allard, Gill, \& Saindon, 1997).

\section{About the Novel and Movie Being There}

The main character in the novel Being There is a simple gardener named Chance. Chance has lived most of his life in seclusion and knows about the world only through television. In the course of the novel he is elevated to the realms of the rich and powerful through a series of misunderstandings. 
Many of these misunderstandings are based on statements Chance makes about gardening, such as "in a garden ... growth has its season" (Kosinski, 1971, p. 45). Chance means these statements literally; however, his interlocutors interpret them as figurative and insightful comments on the economy and political state of the country

As a satire of modern life and politics, the novel touches on a multitude of issues and lends itself to countless oral and written communication activities. Its richness of metaphor also stimulates critical thinking and invites literary analysis. Nonetheless, the level of language is comprehensible even for intermediate learners, and its relatively short length of just over 100 pages makes it adaptable to most class schedules.

Like the novel, the movie has met with international acclaim. Directed by Hal Ashby, the film features Peter Sellers as Chance and equals the book in artistic quality and depth. Yet the movie deviates from the novel in enough instances to represent a new and interesting entity ideal for comparison and classroom discussion.

\section{Reading the Novel}

To allow for manageable homework, we have divided the novel into 10 sections of about 10 pages each. The book can thus be covered as one uninterrupted unit in as little as two weeks (10 days) or spread out over the course of a term if one day per week is set aside for the purpose. We suggest that students read the section assignments at home so that in-class time can be devoted entirely to the activities accompanying the novel. Depending on teachers' and students' preferences, any or all of the following activities can be carried out to explore the book's content and promote language learning.

\section{Free Association Warm-Up}

Before students start reading the novel, we suggest doing an oral free association activity that serves as a warm-up for the whole unit. During this activity, students sit in a circle and are shown a picture related to the theme of the novel to which they respond with spontaneous associations of ideas and feelings. The picture can be an original work of art, a page from a magazine, a poster, or any other picture. In the case of Being There, we use a semiabstract design of plants and a human figure. This picture usually elicits free associations about the students' relationship with nature, experiences with gardening, wilderness trips, environmental issues, and comparisons between the flora found in North America and that of the students' home countries. Many of these issues reappear when students read the novel, because nature and nature metaphors represent an important part of Chance's story. 
Picture Card

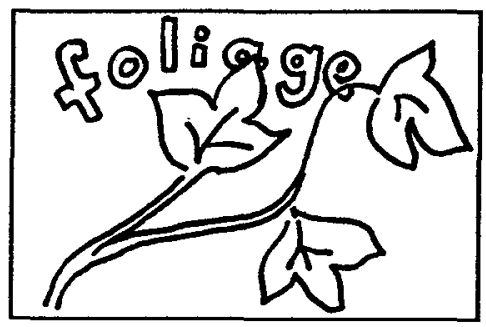

Sentence Card

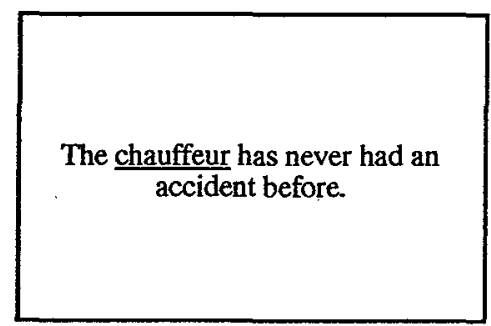

Figure 1. Picture pairs for card games.
Matching Card

Many tourists visit Canada in the fall to see the red and yellow leaves.

\section{Matching Card}

The driver has an excellent driving record.

\section{Vocabulary Development}

Authentic literature often contains words and phrases unfamiliar to. ESL/EFL students. To address this problem we suggest that teachers introduce a variety of techniques to help students increase their vocabulary while making the learning process enjoyable. Techniques we have used successfully include guessing vocabulary from context, keeping a vocabulary journal, playing vocabulary games, and exploring new words and phrases in small groups.

\section{Guessing Vocabulary from Context}

Before reading the novel, students should become familiar with vocabulary guessing techniques that help them understand the text as completely as possible without spending an undue amount of time looking up words in the dictionary. Guidelines include the use of contextual clues, the study of prefixes and suffixes, and comparisons with related words from English word families or the students' native languages. For practice in these guessing techniques, we supply students with the following list of questions to which they can refer when coming across an unfamiliar expression.

1. Does the whole context suggest a particular meaning? 
2. Do you know prefixes, stem, or suffixes of the word?

3 . Can you think of related words?

4. Is there a word in your language that looks or sounds similar?

We encourage students to read all section assignments twice. During the first reading students should try to guess unfamiliar vocabulary and avoid consulting their dictionaries. During the second reading, they should look up and note only those words that cannot be guessed and that are important or of personal interest to them.

\section{Vocabulary Games}

Another prereading vocabulary activity involves playing card games, for which picture or sentence prompts and matching counterparts need to be created. The picture pairs show a word and a respective visual on the prompt card and a synonym in a contextual sentence on the matching counterpart. Sentence pairs feature a word embedded in a sentence on one card and a paraphrase on the other. The prompt sentence can be a quote from the novel containing the word or an original sentence.

Using the matching picture and sentence cards, different games can be played. In the game Concentration, for example, cards are placed on a table face down and then turned over to find pairs. If a student turns over two cards and finds a pair, he or she can keep the cards. If the cards do not match, they have to be returned face down, and another student can try.

Mix ' $n$ ' Match is a game during which students intermingle to find matches for their cards among fellow students. Each student receives several cards and eliminates them one by one as he or she finds the matching counterparts. During Password, students attempt to communicate words from picture or sentence prompts to the class by using synonyms, antonyms, fill-in-the-blank examples, or by telling a story. Students have one or more prompts and take turns until all words have been guessed.

To play the games as a prereading activity, teachers have to select the vocabulary and create the cards. The games can also be played as a postreading activity, but with the students choosing the words and designing the cards themselves. Like the free association activity, the visuals for the picture prompts can be original drawings or cutouts from magazines or newspapers. Keep a stack of old magazines and newspapers in the classroom for this purpose.

The games can be played with only one, several, or all of the 10 reading assignments. If the games are played with several or all reading assignments, cards from earlier reading sections can be mixed with current ones to increase the games' difficulty level and to reinforce previously covered vocabulary. 


\section{Keeping a Vocabulary Journal}

Students are encouraged to keep journals in which they list words of interest from the novel. Keeping vocabulary journals is valuable because students are allowed to make their own decisions on whether a word is important enough to be looked up and noted. Because students make their own word choices, they not only take responsibility for the task of increasing their vocabulary power, but also experience the pleasure of learning words that have particular personal significance, whether work-related, study-related, or of a purely emotional nature.

\section{Vocabulary Group Activity}

In addition to vocabulary guessing, playing games, and keeping a journal, we offer a postreading small-group activity that varies for each reading section. In an exercise called Top Ten List, for example, students create a list of the 10 most important words for one of the novel's characters. In Word Search, the teacher calls out a category (such as nouns that start with the letter $B$, verbs that have two syllables, or rhyming words), and students have five minutes to find at least 10 words in the novel that fit this category.

At regular intervals the students' vocabulary journals are used to supply words for the group activity. Exercises include grouping new vocabulary according to categories, using the words in collaborative poems or stories, and relating new words to similar ones in word webs.

\section{Comprehension Quizzes}

Although vocabulary development is an important part of literature-based classes, the core of each lesson is the exploration of the novel's or play's content. To address basic comprehension issues (as well as add a little motivation for students to come to class prepared), we start class meetings with a comprehension quiz (true/false or multiple-choice). Comprehension quizzes are short and easy so that they can be completed after one or two readings of the respective assignment; they should not require memorization. After students complete the quiz for a reading assignment, the correct answers are discussed in class so that basic comprehension of the reading assignment is assured before going on to more involved activities. The following is an example for a true/false question:

\section{The main character is called Coincidence.}

T $\quad \mathrm{F}$

The question is easy to answer if one has read the text; however, it also plays on the word chance and thus invites discussion on its significance in the novel. If quiz questions are designed to elicit such exploration, they function not only as testing instruments, but also as tools for language learning and critical thinking. 


\section{Discussions and Writing Topics}

The quiz is followed by an open-ended whole- or small-group discussion that is facilitated by the teacher or by student gatekeepers who make sure the discussion stays on track, encourage everyone to participate, mediate misunderstandings, and summarize results at the end. We include discussion questions that examine the content of the novel, but also questions focusing on literary analysis (e.g., of metaphors), cross-cultural comparisons, and topics stimulating personal and affective sharing. The following are possible questions for the first chapter of Being There.

1. In the novel, plants and nature are used as metaphors for various aspects of human society. Which parts of the garden description on the first page could be seen as metaphors? Explain.

2. Chance has lived in seclusion all his life, content with only his garden and TV. Imagine that you would have to live in a place that is surrounded by a high wall. If you could take only 10 things to that place, what would they be?

3. Chance watches a lot of TV. How does TV programming in your country differ from that in Canada or the United States? What positive or negative effects does watching TV have, in your opinion?

4. What do we know about Chance's parents? What are some questions that you would like to have answered about Chance's life?

Discussion questions can also be used as writing topics and expanded to include research assignments on the novel, the author, or any theme related to the content. Thus questions (such as the one on TV programming in the list above) can be further explored through library research, surveys or interview with native speakers, and Internet searches. Students may find the Being There home page interesting, for example, which includes information on Jerzy Kosinski and Peter Sellers as well as reviews of the movie (see http://www.geocities.com/Hollywood/8200/being.html).

\section{Whole-Language Activities}

We follow class discussions with a number of whole-language activities that allow students to learn language holistically as they use all four skills while engaging in meaningful and functional social interactions. Many of these activities are based on a journal that students keep as they read the novel. In this reading journal, students write passages from the novel that affect them in some way-perhaps because they identify with a character, because they had an experience similar to that being described, or because something about the passage appeals to them. They may also want to quote a passage if the language is interesting to them, for example, because it contains exciting, vivid, or poetic writing. They may write down a passage that they cannot understand. No matter what they choose, they should record the quotation from the novel on one page of their journal, and on the facing page explain 
why they selected the particular passage by noting what was interesting about it. An entry should be made for every reading assignment, and the reading journal is the regular focus of small-group work in class. Students consult their journals and get together to share their feelings and thoughts about the reading. They are thus able to relate the material they have read to their own experiences and beliefs and interact with their classmates in a supportive environment.

Not all whole-language activities have to be based on the reading journal. Alternative activities include the collaborative creation of plot summaries, comparing and contrasting events, and charting character traits on mind maps. Large pieces of flipchart paper or posterboard should be provided so that group results can later be exhibited and discussed in class.

\section{The Video Project}

After the novel has been read and before the students watch the movie, a video project provides a stimulating and exciting opportunity for hands-on experience and application of the previously covered material. Students select a passage in the novel that appeals to them and that they hope the director will have included in the film version. The students then work on this passage, with the goal of personally videotaping a version of it. Teachers may opt for an abbreviated video project, including only the writing, rehearsing, and performing of a dialogue based on the passage of the novel. However, if time is available, the process may be expanded to allow for more intense involvement and diversified tasks. Such an involved video project would include pre-production activities (such as drawing a storyboard, and writing a screenplay and shooting script), rehearsing and filming the final product, and possibly an opening night celebration complete with invited guests, refreshments, and achievement awards for actors and crew (Marcus, 1977; Rose, 1996). Students can thus choose among a variety of roles. Some can draw the storyboard while some others write the screenplay or shooting script. They need to appoint a director, actors, a camera operator, and someone responsible for scheduling, props, set, and costume design. If so desired, makeup, music, and special effects could be supplied. In addition, a student or group of students can create a poster for the performance, make plans for opening night, and function as announcers during the award ceremony. Actors and crew members can participate in physical and vocal warm-up exercises similar to those used by professional actors, which are an excellent tool for team building and practicing pronunciation, intonation, and expressiveness (Wessels, 1987).

Needless to say, the production of a movie comprises so many roles and problem-solving experiences that a suitable task can be found for just about any learner and learning style. Furthermore, the project creates a natural environment that promotes authentic communication and the transfer of 
skills practiced in controlled settings to realistic contexts. Students tend to be highly stimulated by the experience and communicate with commitment and true interest.

\section{Watching the Movie}

After reading the novel and completing the video project, a final activity set focuses on the movie version of the novel. We start with a previewing discussion that focuses on students' expectations of the film with regard to locale, actors, and possible deviations from the novel. Because endings are often changed in film adaptations of literature, we include one question eliciting predictions about the movie's ending. Students find it especially interesting to discuss how an open or sad ending in the book may be altered to make it more definite or positive, thus aligning it with current practices in the mainstream movie industry that prefers happy endings for marketability reasons.

Activities can also be carried out during the actual viewing of the film. Examples include cloze dictations of dialogues (previously transcribed by the teacher), prediction exercises concerning dialogue and content, and jumbled dialogues to be put in the correct order by student groups. Movies provide an excellent vehicle for language learning, and teachers should consider reserving enough time for these activities to exploit the medium's potential. For more ideas, teachers may want to consult one of the reference manuals available for the use of video in the language classroom (Lonergan, 1984; Stempleski \& Tomalin, 1990; Stempleski \& Arcario, 1992; Williamson \& Vincent, 1996).

After screening the film, we recommend a number of postviewing activities. Students can compare the book and movie and discuss issues contained in the film, but not the novel or play. In the movie Being There, for example, a physician has a substantial role that is virtually absent in the book. This deviation can be used to explore the differences between the two media and to discuss their advantages and limitations.

Students can also voice their opinions about the movie by writing a film review in the style of their favorite newspaper of magazine. Similarly, students may want to stage a debate between two film critics, one arguing for and one against the movie. In addition, advanced students may find it interesting to analyze the movie according to well-known schools of film theory. Examples include feminist, Marxist, semiotic, and psychoanalytic theory (focusing on issues related to women, class struggle, language-like structure, and psychological factors respectively). For more information on these approaches, see film theory texts such as An Introduction to Film Criticism by Bywater and Sobchack (1989). 


\section{Conclusion}

Literature and film in the classroom are appealing for many reasons. With only a little preparation, the two media can be used to teach language and to address diverse learning styles. Activities lend themselves to individual and group work and are interesting and motivating because they frequently use student-generated material. By reading a novel, conducting a video project, and watching the movie, students can improve their language competence in a holistic and highly satisfying manner. It does not come as a surprise, therefore, that students often ask, "What are we going to read next?" after one novel and its movie version are finished. This enthusiasm is music in the ears of teachers.

\section{The Authors}

Elisabeth Gareis teaches ESL, speech, and intercultural communication at Baruch College/CUNY. She currently serves as Chair of the TESOL Video Interest Section. Her research interests include oral communication for academic purposes and intercultural friendship.

Martine Allard has an MEd in adult education with a special field concentration in ESL. She was head of EFL studies at the NATO Headquarters in Brussels, Belgium for 10 years and has taught ESL/EFL in the United States and Norway. She is currently teaching at Seneca College in Toronto, Canada.

Susan Gill teaches ESL at the American Language Program, University of Georgia in Athens, Georgia, USA. Her curriculum packages focusing on games and visual imagery have been used in her own classes and in Boston University's Intergenerational Literacy Project, Clarke County Georgia's ESOL Center, and the Carter Presidential Center in Atlanta.

Jacqueline Saindon has a master's degree in anthropology and a doctorate in adult education. She teaches ESL at the American Language Program, University of Georgia, and Anthropology at Brenau University, both in Georgia, USA.

\section{References}

Bywater, T., \& Sobchack, T. (1989). An introduction to film criticism. New York: Longman.

Gareis, E., Allard, M., Gill, S., \& Saindon, J. (1997). A novel approach: Being there. Ann Arbor, MI: University of Michigan Press.

Kosinski, J. (1971). Being there. New York: Harcourt Brace Jovanovich.

Lonergan, J.P. (1984). Video in language learning. Cambridge: Cambridge University Press.

Marcus, F.H. (1977). Short story/short film. Englewood Cliffs, NJ: Prentice-Hall.

Rose, R.L. (1996). Student-produced videos: Practical tips for memorable productions. TESOL Video News, 7(2), 3, 7,9.

Stempleski, S., \& Arcario, P. (Eds.). (1992). Video in second language teaching: Using, selecting, producing video for the classroom. Alexandria, VA: Teachers of English to Speakers of Other Languages (TESOL).

Stempleski, S., \& Tomalin, B. (1990). Video in action: Recipes for using video in language teaching. Englewood Cliffs, NJ: Prentice-Hall.

Wessels, C. (1987). Drama. New York: Oxford University Press.

Williamson, J.A., \& Vincent, J.C. (1996). Film is content: A study guide for the advanced ESL classroom. Ann Arbor, MI: University of Michigan Press. 